\title{
Krukenburg Tumour Presented as Multiple Abdominal Lumps - A Case Report
}

\author{
Ahmed $\mathrm{S}^{1}$, Singha $\mathrm{JL}^{2}$, Ahmed $\mathrm{N}^{3}$
}

Conflict of Interest: None Financial Support: None Received: 13 April 2017 Accepted: 20 May 2017 www.banglajol.info/index.php/JSSMC

\section{Key Words:}

Krukenberg tumour, metastatic adenocarcinoma, gastric adenocarcinoma, signet ring cell carcinoma, palliative chemotherapy, surgical resection.

\begin{abstract}
:
Krukenberg tumour is metastatic ovarian involvement of adenocarcinoma in women of reproductive age group. The primary site is commonly in stomach but less commonly from other parts of gastrointestinal tract and uncommonly from other organs. The route of metastasis of this tumour is still not proven though the raw ovarian surface and transperitoneal invitation of malignant cell is one of the postulations. As is the etiology so is the resection of either ovarian or gastric tumour failed to show any improvement of this condition. Ovarian resection can be done in the form of salphingo-oophorectomy with or without hysterectomy. Gastric resection is also done in the same or subsequent sitting according to stage and presentation.
\end{abstract}

We report such an uncommon entity in a 33 year old lady presenting with lower abdominal lump.

[J Shaheed Suhrawardy Med Coll 2017; 9(1): 38-40] DOI: http://dx.doi.org/10.3329/jssmc.v9i1.37259

\section{Introduction:}

In the year 1896 krukenberg presented 5 cases of peculiar ovarian tumours having appearance of malignancy. He thought those as new type of primary ovarian sarcoma which he named 'fibrosarcoma ovarii mucocellulare (carcinomatodes)" ${ }^{\prime 1,2}$. In his thesis he proved it as a primary tumour of ovary but later it was proved to be nearly always secondary to gastrointestinal tract malignancy particularly stomach $^{3}$.

However, there have been rare and isolated cases which have been interpreted as primary tumour. Other primary GI organs are colon, jejunum, biliary tree and pancreas. Non GI organs usually are breast, uterine endometrium, thyroid, kidney and lungs ${ }^{4}$. Nearly $80 \%$ of cases are bilateral. Histologically these are usually poorly differentiated intestinal type adenocarcinoma with or without signet ring cells and sometimes producing

1. Dr. Sami Ahmad, Associate Professor, Department of Surgery, Shaheed Suhrawardy Medical College, Dhaka.

2. Dr. Jawhar Lal Singha, Assistant Professor, Department of Surgery, Shaheed Suhrawardy Medical College,Dhaka.

3. Dr. Nadim Ahmed, Senior Consultant, Department of Surgery, Shaheed Suhrawardy Medical College,Dhaka.

Correspondence to: Dr. Sami Ahmad, Associate Professor Surgery, Shaheed Suhrawardy Medical College,Dhaka. Email: dr.sami39 @gmail.com mucins ${ }^{5}$. With this pathological picture it is considered metastatic disease with very poor prognosis. Till date, optimal treatment has not been established and it is still uncertain whether surgical resection of ovarian metastasis and / or the primary tumour could help. We, herewith, report such a case where the lady presented with ovarian tumours but ultimately was diagnosed as 'Krukenberg tumour' of which the primary was in her stomach.

\section{The case:}

A $33 \mathrm{yr}$ old housewife was admitted to Shaheed suhrawardy medical college hospital on $13^{\text {th }}$ September, 2017 with the complaints of epigastric fullness, discomfort and vomiting after meal for 6 months. She had anorexia and significant weight loss for 4 months. She was ill looking with below average body built. She was malnourished and moderately anemic. On examination there was an intra-abdominal mobile lump measuring about $3 \mathrm{~cm} \times 3 \mathrm{~cm}$ in the epigastric region which was firm in consistency, non-tender with irregular surface and ill defined margin. Ascites was present. There was another intra-abdominal mobile lump in the left iliac region measuring about $4 \mathrm{cmx} 3 \mathrm{~cm}$, firm in consistency, nontender with smooth surface but ill-defined margin. 


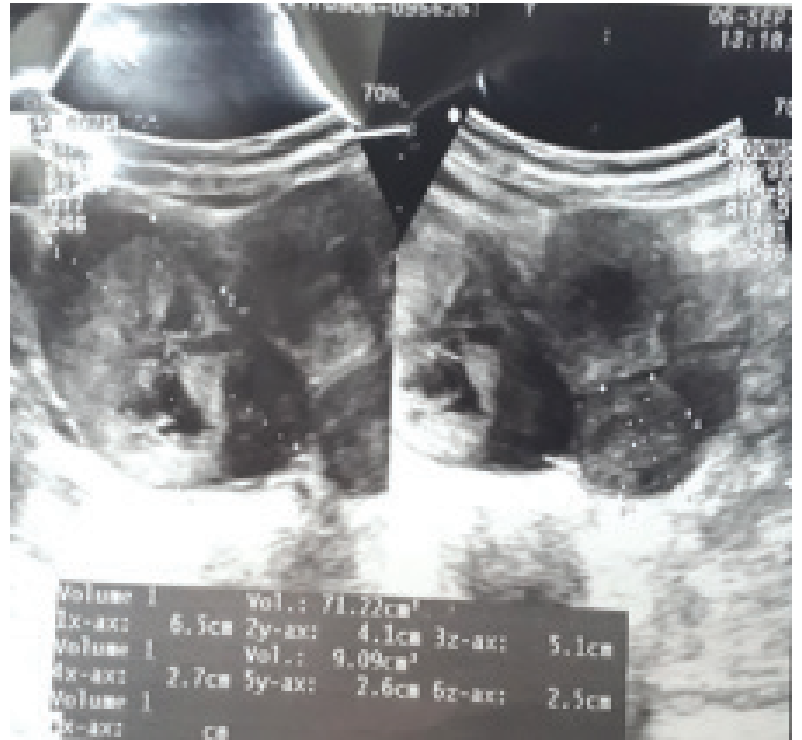

Fig-1: Intra abdominal masses.
Bilateral mobile adnexal masses were felt on per vaginal and per rectal digital examination which were separate from uterus. Other system examination revealed no abnormality. She was anemic (Hb-9.5 gm/dl) with electrolyte imbalance (Na- 136meq/1, K- 3meq/1, Cl- 99 meq/l). Ultrasonogram revealed(figure 1) thickened pyloric part of stomach causing huge dilatation of stomach, moderate ascites and bilateral adnexal masses.

Upper GI endoscopy showed gastric outlet obstruction which may be due to carcinoma stomach, lymphoma, chronic gastric ulcer disease (figure-2). Endoscopic biopsy report was chronic gastritis. Pre and post contras CT scan of whole abdomen reported as gastric outlet obstruction, right adnexal mass and prominent left ovary (fig - 3). Tumour markers showed CA 19-9 51.6U/ml (N: $<37)$, CA $1259 \mathrm{u} / 1(\mathrm{~N}:<35)$. On diagnostic laparoscopy we found malignant looking mass involving lower part of stomach and both ovaries. Uterus was healthy.

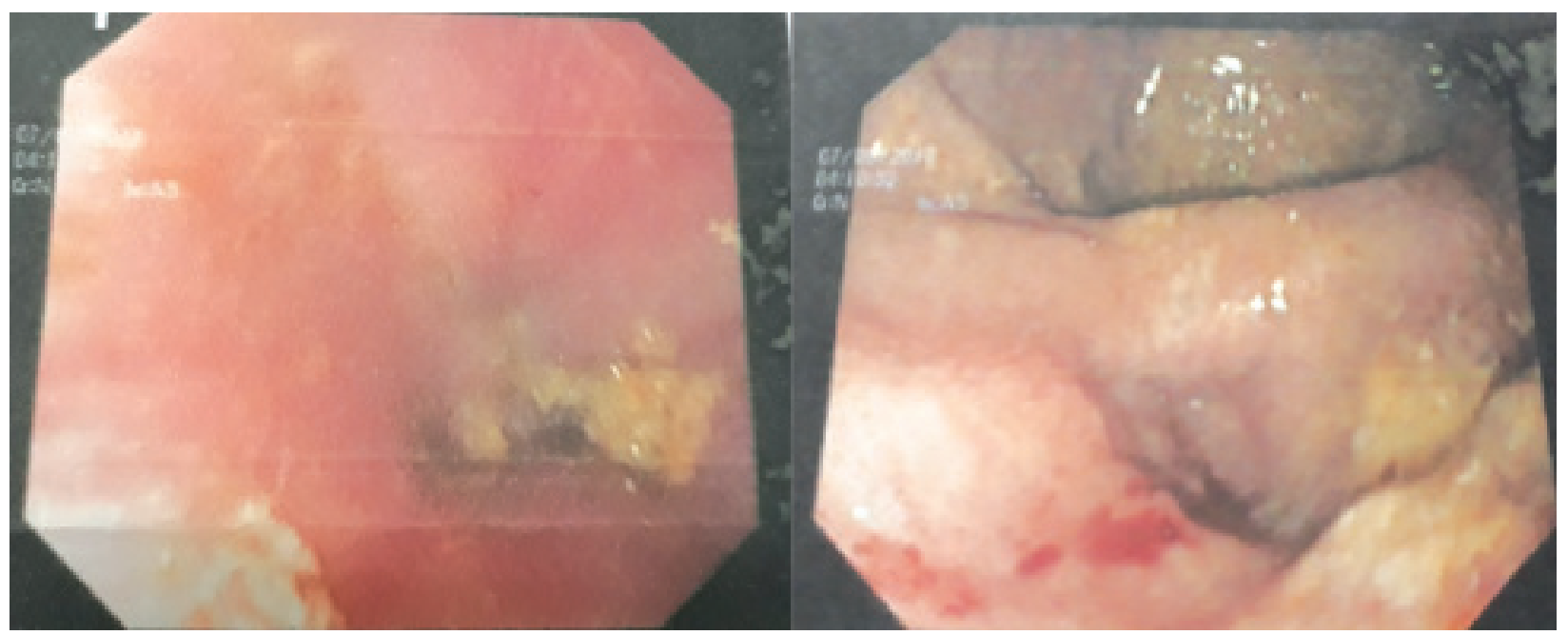

Fig-2: Upper GI endoscopy shows ulceration at the pylorus.

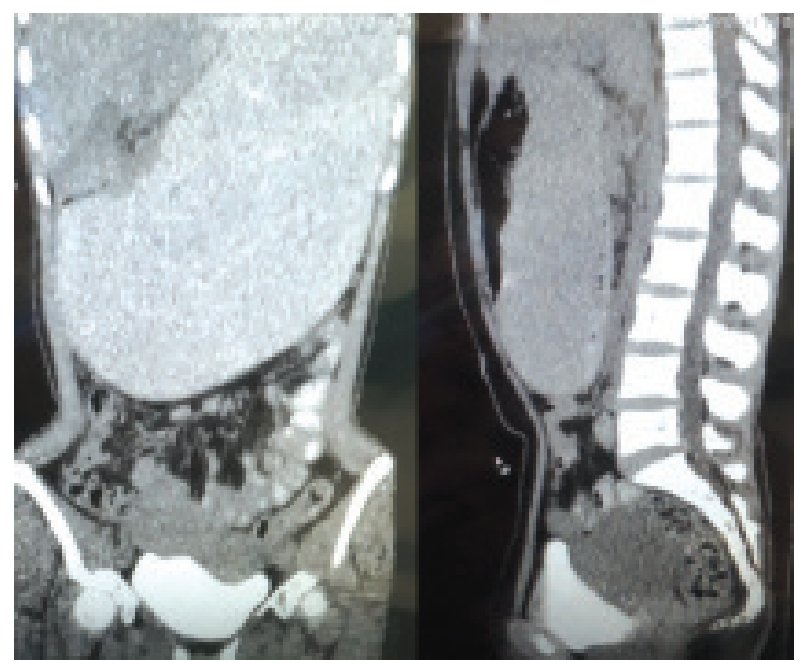

Fig-3: CT scan shows huge dilatation of stomach and pelvic mass.

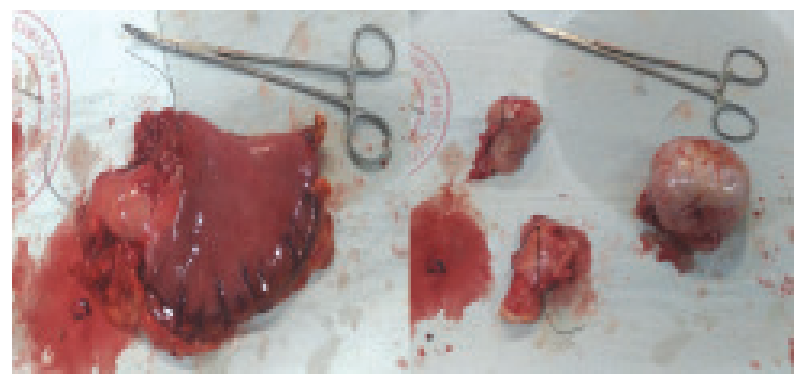

Fig-4 : Part of stomach and uterus and both ovaries following surgery.

Lower partial gastrectomy and gastrojejunostomy was done. Total abdominal hysterectomy and bilateral salphingoophorectomy were done by gynecologist fig-7). 
Histopathology report revealed:

Uterus - no tumour cell found.

Left ovary - poorly differentiated adenocarcinoma

Right ovary - poorly differentiated adenocarcinoma.

Fallopian tubes - both are free from tumour.

Stomach - adenocarcinoma, poorly differentiated mucinous type. Mucin lakes with signet ring type cells are noted.

\section{Discussion:}

Krukenberg tumour constitute $1 \%$ to $2 \%$ of all ovarian tumour usually presents in younger female with average age of 45 years ${ }^{3,6}$. Most of the cases originate from gastric adenocarcinoma. In majority of cases they are synchronous but $20 \%$ to $30 \%$ of cases appear metachronous. The route of spread of this lesion is still not well established. As the tumour is usually well encapsulated and rarely shows any ovarian surface involvement, theory of peritoneal seeding from primary lesion is questioned. Rich lymphatics draining gastric mucosa and submucosa initiating retrograde lymphatic spread to ovary is mostly accepted theory. Few authors favour haematogenous spread through thoracic duct ${ }^{7}$. The prognosis of a patient of krukenberg tumour is extremely poor with average survival time is between 3 and 10 months. Only $10 \%$ of patients survive more than two years after diagnosis ${ }^{8}$. Treatment of patient of krukenberg tumour is controversial. Some studies have investigated the role of removing the tumour originated from stomach and demonstrated that resection of ovarian metastasis might prolong survival ${ }^{9}$. Some other studies suggested that metachronous ovarian metastasis or unilateral ovarian metastasis might correlate with good survival and ovarian metastasectomy may be beneficial when gross residual diseases being thoroughly eradicated ${ }^{10}$. I a retrograde analysis of 133 patients with krukenberg tumour the author concluded that ovarian metastasectomy might be helpful for prolonging the survival of some patients with krukenberg rumour originating from stomach. Patients without ascites and with resected primary gastric cancer could get benefit from and be potential candidate for surgical treatment. They did not recommend patients to undergo ovarian metastasectomy if the primary stomach lesion hadn't or couldn't been resectedor ascites was detected $^{5}$.

Our patient was originally a case of gastric adenocarcinomawith synchronous ovarian metastasis hence the diagnosis was made as krukenberg tumour. Here patient underwent lower partial gastrectomy and hysterectomy with bilateral salphino-oophorectomy. Preoperative chest $\mathrm{x}$-ray and per-operative finding did not reveal any chest or para aortic lymph node involvement. A few sub pyloric lymph nodes were enlarged and removed. After recovery from surgery expert opinion from oncologist was taken and the patient was under his subsequent treatment.

\section{Conclusion:}

In any patient presenting with ovarian neoplasm we should look for other symptoms of patient and investigate accordingly. Upper GI endoscopy, colonoscopy, tumour marker like CA 19-9, CEA and CA 125 may help us to get the clue of origin of the primary tumour if suspicion of krukenberg tumour is made.

\section{Acknowledgements.}

The authors declare no conflict of interest.

\section{References:}

1. Krukenberg, Friedrich: Fibrosarcoma ovarii mucocellulare (carcinomatoides) Arch.f.Gynak,50,287-321,1896.

2. KimSH, Kim WH, Park KJ, et al,CT and MRI findings of Krukenberg tumors: comparison with primary ovarian tumors. J Comput Assist Tomogr1996;20:393-8.

3. Al- Agah OM, Nicastri AD. An in-depth look at Krukenberg tumor: an over view. Arch Pathol Lab Med 2006;130:172530 .

4. Lash RH,Hart WR. Intestinal adenocarcinomas metastatic to the overies. A clinico pathologic evaluationof 22 cases.Am J Sur Pathol 1987;11:114-21

5. Peng W, HuaRX, Jiang R et al. Surgical treatment for patients with Krukenberg tumor of stomach origin: clinical outcome and prognostic factors analysis. PL oS One 2013; 8:: e68227.

6. Young RH, From Krukenberg to today: the ever present problems posed by metastatic tumors in the overy: part !. Historical perspective, general principles, mucinous tumors including the Krukenberg tumors.Adv anat Pathol2006;13:205-27.

7. Taylor AE, Nicolsion VM. CunninghamD. Overian matastastases from primary gastrointestinal malignancies: thr Royal Marsden Hospital experience and implications for adjuvant treatment. Br. J Cancer 1995; 71: 92-6

8. Yook JH, Oh ST, Kim BS. Clinical prognostic factors for ovarian metastasis inwomen with gastric cancer. Hepatogastroenterology 2007;54:955-9.

9. Mc Gill FM, Ritter DB, Richard CS et al . Krukenberg tumors: can management be improved? Gynecol Obstet Invest 199; 48: $61-5$.

10 .Jun SY, Park JK. Metachronus orarian metastases following resection of the Primary gastric cancer. J Gastric Cancer 2011;11:31-07 